\title{
Ferrofluid Lubrication of a Rough Porous Secant-Shaped Slider Bearing with Slip Velocity
}

\author{
J. R. Patel ${ }^{*}$, G. M. Deheri², S. J. Patel ${ }^{2}$ \\ ${ }^{1}$ Department of Mathematical Sciences, P D Patel Institute of Applied Sciences, CHARUSAT, \\ Changa, Anand, Gujarat, India - 388421 \\ e-mail: patel.jimitphdmarch2013@gmail.com \\ ${ }^{2}$ Department of Mathematics Sardar Patel University \\ VallabhVidyanagarAnand, Gujarat, India - 388120 \\ e-mail: gm.deheri@rediffmail.com, sejal.patel85@yahoo.com \\ *corresponding author
}

\begin{abstract}
This article aims to discuss the combined effect of roughness and slip velocity on the performance of a ferrofluid based rough porous secant shape slider bearing. The slip model of Beavers and Joseph has been deployed to study the effect of velocity slip while the stochastic model of Christensen and Tonder has been used to calculate the effect of surface roughness. The concerned statistically averaged Reynolds' type equation is solved with suitable boundary conditions to obtain the pressure distribution leading to the calculation of load carrying capacity. Further, the expression for friction and the position of center of pressure are obtained. It is observed that the bearing suffers due to surface roughness. However, this adverse effect can be reduced considerably by the ferrofluid lubrication taking the slip parameter at minimum. In this type of bearing system, the combination of slip velocity and skewness may play a crucial role in augmenting the bearing performance. Besides, the friction is found to be mostly decreasing or nominally increasing.
\end{abstract}

Keywords: Secant-shape slider, ferrofluid, roughness, slip, load and friction

\section{Introduction}

Agrawal (1986) analyzed an inclined plane slider bearing having a porous-faced stator with a ferrofluid lubricant and observed that its performance was relatively better than the corresponding bearing with a conventional lubricant. It is well-known that the slider bends due to elastic, thermal or uneven wear effects. Cameron (1987) proposed an exponential form of the slider to be nearest the true shape. Bhat and Patel (1991) considered an exponential slider with a porous-faced stator working under a ferrofluid lubricant. Such a lubricant increases the load without altering the friction. Salant and Fortier (2004) conducted a numerical analysis on the performance of a slider bearing and established that with a critical shear stress of zero, a significant increase in load support and decrease in friction could be achieved with an 
appropriate surface pattern. Later on, Deheri et al. (2005) developed and modified the analysis of above problem considering a magnetic fluid as the lubricant. The magnetic fluid lubrication not only increased the load carrying capacity but also diminished the adverse effect of transverse roughness up to considerable extent. Wu et al. (2006) discussed the lubrication behavior of infinite width slider bearing involving a mixed slip surface. Surface optimization of a parallel sliding gap with a slip surface doubled the hydrodynamic load support and reduced the friction drag by half of what the Reynolds theory predicted for an optimal wedge of a traditional slider bearing.

In the fluid dynamics, the no-slip condition for viscous fluids states that at a solid boundary, the fluid will have zero velocity relative to the boundary. But it was noticed that this phenomenon was not always true. The fluid will have some velocity relative to the solid boundary; this velocity is defined as slip velocity. It was found that faster response of the squeeze time was in place by considering the velocity slip on porous walled squeeze film and by suitable values of slip velocity.

The 'no-slip' is a fundamental assumption and generally-accepted boundary condition in rheology, tribology and fluid mechanics with strong experimental support. The violations of this condition, however, are widely recognized in many situations, especially in the flow of nonNewtonian fluids. In the flow of viscous fluids over solid surfaces, the 'no-slip' at the fluidsolid interface is a widely-accepted boundary condition with many important consequences. The essence of this condition is the continuity of the tangential component of the velocity at the wall due to the fact that viscous fluids stick to the solid surface Strictly speaking, no-slip means that the instantaneous relative velocity between the fluid and surface, as well as its time average, is zero.

Beavers and Joseph (1967) proposed a simple theory based on replacing the effect of the boundary layer with a slip velocity proportional to the exterior velocity gradient and proved it to be in reasonable agreement with experimental results. Sparrow et al. (1972) analyzed the fluid flow processes in a squeeze film having one porous bounding wall. The results established that porous media were effective in diminishing the response time of the squeeze film. Substantially faster response was attained by the use of porous materials with accentuate velocity slip. Patel and Gupta (1983) analyzed the effect of slip velocity on the hydrodynamic lubrication of an inclined porous slider bearing. Minimization of slip parameter remained essential to augment the performance of the bearing system. Shah and Bhat (2003) studied the performance of a porous exponential slider bearing with a ferrofluid lubricant, whose flow was governed by Jenkins model, considering slip velocity at the porous interface. The slip parameter decreased the load carrying capacity without significantly affecting the centre of pressure. Patel and Deheri (2011) investigated the performance of a transversely rough porous parallel plate slider bearing under the presence of a magnetic fluid, considering the slip velocity. For a better performance it was established that the slip parameter deserved to be kept at minimum, even if a suitable magnetic strength was in force. Patel and Deheri (2014) dealt with the effect of a magnetic fluid based infinitely long rough bearing considering slip velocity. It was established that keeping the slip coefficient at minimum, the magnetization might compensate the adverse effect of the standard deviation.

Prakash and Vij (1973) and Ajwalia (1984) analyzed slider bearings with conventional lubricants by taking the slider to be plane and secant-function shaped, respectively. Andharia et al. (2001) considered the effect of transverse surface roughness on the hydrodynamic lubrication of slider bearings with various film shapes. Here, for the hyperbolic slider bearing it was found that the combined effect of positively skewed roughness and standard deviation caused severe load reduction. Nanduvinamani et al. (2003) discussed the combined effects of couple stresses and surface roughness on the performance characteristics of hydrodynamic 
lubrication of slider bearings with various film shapes, such as plane slider, exponential secant and hyperbolic. It was noticed that the load increased due to couple stress effect for all above geometries. The effect of longitudinal surface roughness on the behavior of slider bearing with squeeze film formed by a magnetic fluid was analyzed by Deheri et al. (2004) In order to investigate the qualitative effect of roughness on the performance characteristics, four shapes namely; plane slider, exponential slider, hyperbolic slider and secant slider for the lubricant film were considered. It was observed that the bearing performance was significantly affected by all three parameters characterizing the surface roughness. Bujurke et al. (2005) studied the combined effects of permeability and couple stress on the performance characteristics of a secant-shaped porous slider bearing lubricated with Stokes couple stress fluid. It was found that the effect of couple stress was to increase the load carrying capacity and to decrease the coefficient of friction. Shukla and Deheri (2011) discussed the effect of transverse surface roughness on the performance of a magnetic fluid based porous secant shaped slider bearing. It was established that the negative effect of porosity and standard deviation could be minimized to a large extent by the effect of magnetization at least, in the case of negatively skewed roughness. The friction was reduced when variance [-ve] involved. Patel and Deheri (2013) investigated the comparison of various porous structures on the performance of a magnetic fluid based transversely rough short bearing. Siddangouda et al. (2014) analyzed the combined effects of micro polarity and surface roughness on the hydrodynamic lubrication of slider bearings with different film shapes including secant-shaped slider bearing. Here, the negatively skewed roughness increased the load carrying capacity and temperature as well. Patel and Deheri (2015) dealt with the comparison of the performance of a Jenkins model based magnetic squeeze film in curved rough circular plates considering slip velocity for different shapes of the surfaces. It was observed that for the exponential shape the combined effect of magnetism and negatively skewed roughness was relatively more, even for higher values of slip parameter. Recently, Patel and Deheri (2016) have examined the effect of slip velocity on the performance of a magnetic fluid based squeeze film in conical plates considering the longitudinal roughness pattern.

Here, it has been proposed to launch an investigation into the performance characteristics of a rough porous secant-shaped ferrofluid based slider bearing with slip velocity.

\section{Fundamental relations}

The configuration of the bearing system is presented below.

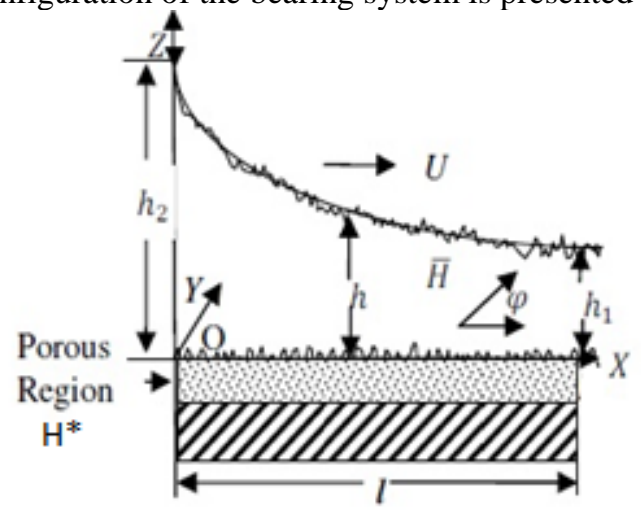

Fig. 1. Configuration of bearing System 
The bearing system consists of a slider in secant form moving with a uniform velocity $U$ in the $\mathrm{x}$-direction and a stator with a porous matrix of thickness $\mathrm{H}^{*}$.

Here $\mathrm{l}$ is the length and $\mathrm{b}$ is the breath of the bearing with $\mathrm{l}<<\mathrm{b}$. In view of the discussions of Cameron (1987) the film thickness $h$ can be defined as:

$$
\mathrm{h}=\mathrm{h}_{2} \sec \left(-\frac{\mathrm{xln} a}{\mathrm{l}}\right), \quad 0 \leq \mathrm{x} \leq \mathrm{l}
$$

where

$$
a=\frac{h_{2}}{h_{1}}
$$

$h_{2}$ is the maximum value of $h$ and $h_{1}$ is the minimum value of $h$.

Following the investigations of Agrawal (1986) the magnitude $\mathrm{H}$ of the magnetic field $\overline{\mathrm{H}}$ is taken as:

$$
\mathrm{H}^{2}=\mathrm{Kx}(1-\mathrm{x})
$$

$\mathrm{K}$ being a quantity chosen to suit the dimensions so as to manufacture a magnetic field of required strength. The inclination angle of the magnetic field is determined as in Agrawal (1986). The study carried out in Verma (1986) indicates that the equation of fluid flow in the film region is:

$$
\frac{\partial^{2} \mathrm{u}}{\partial \mathrm{z}^{2}}=\frac{1}{\mu} \frac{\partial}{\partial \mathrm{x}}\left(\mathrm{p}-\frac{\mu_{0} \bar{\mu} \mathrm{H}^{2}}{2}\right)
$$

where $u$ is the $x$-component of the fluid velocity, $\mu$ is the fluid viscosity, $p$ is the film pressure, $\mu_{0}$ is the permeability of free space and $\bar{\mu}$ is the magnetic susceptibility.

Sparrow et.al (1972) proved the following boundary conditions:

$$
\begin{gathered}
u=U \text { when } \mathrm{z}=\mathrm{h}, \\
\mathrm{u}=\left(\frac{1}{\mathrm{~s}} \frac{\partial \mathrm{u}}{\partial \mathrm{z}}\right)_{\mathrm{z}=0} \text { when } \mathrm{z}=0
\end{gathered}
$$

where $\mathrm{s}$ is the slip constant.

Solving Eq. (3) under the boundary conditions (4), substituting the value of $u$ in the integral form of the continuity equation for the film region, using continuity of velocity components of the fluid in the film region and porous matrix across the surface $\mathrm{z}=0$, one arrives at the Reynolds type equation governing the film pressure of (Agrawal (1986), Bhat (2003), Patel et al. (2014):

$$
\frac{\mathrm{d}}{\mathrm{dx}}\left[\left\{12 \mathrm{kH}+\frac{\mathrm{h}^{3}(4+\mathrm{sh})}{(1+\mathrm{sh})}\right\} \frac{\mathrm{d}}{\mathrm{dx}}\left(\mathrm{p}-\frac{\mu_{0} \bar{\mu} \mathrm{H}^{2}}{2}\right)\right]=6 \mu \mathrm{U} \frac{\mathrm{d}}{\mathrm{dx}}\left[\frac{\mathrm{h}(2+\mathrm{sh})}{1+\mathrm{sh}}\right]
$$


where $\mathrm{k}$ is the permeability of the porous material.

The random roughness of the bearing surfaces is characterized by a random variable with nonzero mean $\alpha$, the standard deviation $\sigma$ and the Skewness $\varepsilon$. They are defined as:

$$
\alpha=\mathrm{E}\left(\mathrm{h}_{\mathrm{S}}\right), \sigma^{2}=\mathrm{E}\left[\left(\mathrm{h}_{\mathrm{S}}-\alpha\right)^{2}\right], \varepsilon=\mathrm{E}\left[\left(\mathrm{h}_{\mathrm{S}}-\alpha\right)^{3}\right]
$$

where $\mathrm{E}$ denotes the expected value defined by

$$
E(R)=\int_{-C}^{c} R f\left(h_{S}\right) d s
$$

In line with the discussions of Christensen and Tonder (1969a, 1969b, 1970), the thickness $\mathrm{h}(\mathrm{x})$ of the lubricant film is taken as:

$$
h(x)=\bar{h}(x)+h_{S}
$$

where $\bar{h}(x)$ is the mean film thickness and $h_{s}$ is the deviation from the mean film thickness characterizing the random roughness of the bearing surfaces. $h_{s}$ is considered to be stochastic in nature and governed by the probability density function:

$$
\begin{aligned}
& \mathrm{f}\left(\mathrm{h}_{\mathrm{s}}\right)= \begin{cases}\frac{35}{32 \mathrm{c}}\left(1-\frac{\mathrm{h}_{\mathrm{s}}^{2}}{\mathrm{c}^{2}}\right)^{3}, & -c \leq \mathrm{h}_{\mathrm{s}} \leq \mathrm{c} \\
0, & \text { elsewhere }\end{cases} \\
& \frac{d}{d x}\left[\left\{12 \mathrm{kH}^{*}+\frac{\mathrm{g}(\mathrm{h})(4+\mathrm{sh})}{(1+\mathrm{sh})}\right\} \frac{\mathrm{d}}{\mathrm{dx}}\left(\mathrm{p}-\frac{\mu_{0} \overline{\mu H}^{2}}{2}\right)\right]=6 \mu \mathrm{U} \frac{\mathrm{d}}{\mathrm{dx}}\left[\frac{(\mathrm{g}(\mathrm{h}))^{\frac{1}{3}}(2+\mathrm{sh})}{1+\mathrm{sh}}\right]
\end{aligned}
$$

where

$$
g(h)=h^{3}+4\left(\sigma^{2}+\alpha^{2}\right) h+2 \alpha h^{2}+2 \alpha^{3}+3 \sigma^{2} \alpha+\varepsilon
$$

Making use of Eqs. (1) and (2) and dimensionless quantities:

$$
\begin{aligned}
& \mathrm{X}=\frac{\mathrm{x}}{\mathrm{l}}, \psi=\frac{\mathrm{kH}}{\mathrm{h}^{3}}, \overline{\mathrm{h}}=\frac{\mathrm{h}}{\mathrm{h}_{1}}, \overline{\mathrm{s}}=\mathrm{sh}_{1}, \\
& \mathrm{P}=\frac{\mathrm{h}_{1}{ }^{2} \mathrm{p}}{\mu \mathrm{Ul}}, \mu^{*}=\frac{\mu_{0} \bar{\mu}^{\bar{\mu} \mathrm{h}_{1}{ }^{2}}}{\mu \mathrm{U}}
\end{aligned}
$$

Eq. (6) transforms to:

$$
\frac{d}{d X}\left[G \frac{d}{d x}\left\{P-\frac{1}{2} \mu^{*} x(1-x)\right\}\right]=\frac{d E}{d x}
$$

where 


$$
\overline{\mathrm{h}}=\frac{\mathrm{a}}{1+\mathrm{X} \ln \mathrm{a}}, \mathrm{G}=12 \psi+\frac{\mathrm{g}(\overline{\mathrm{h}})(4+\overline{\mathrm{sh}})}{(1+\overline{\mathrm{sh}})}, \quad \mathrm{E}=\frac{6(\mathrm{~g}(\overline{\mathrm{h}}))^{\frac{1}{3}}(2+\overline{\mathrm{s}} \overline{\mathrm{h}})}{(1+\overline{\mathrm{sh}})}
$$

where in

$$
g(\bar{h})=1+4\left(\bar{\sigma}^{-2}+\bar{\alpha}^{-2}\right)+2 \bar{\alpha}+3 \bar{\sigma}^{-2} \bar{\alpha}+2 \bar{\alpha}^{3}+\bar{\varepsilon}
$$

Solving Eq. (7) under the boundary conditions:

$$
(\mathrm{P})_{\mathrm{X}=0,1}=0
$$

one obtains the expression for dimensionless pressure distribution as:

$$
\mathrm{P}=\frac{1}{2} \mu^{*} \mathrm{x}(1-\mathrm{x})+\int_{1}^{\mathrm{X}} \frac{\mathrm{E}-\mathrm{Q}}{\mathrm{G}} \mathrm{dx}
$$

where

$$
\mathrm{Q}=\frac{\int_{0}^{1} \frac{\mathrm{E}}{\mathrm{G}} \mathrm{dX}}{\int_{0}^{1} \frac{1}{\mathrm{G}} \mathrm{dX}}
$$

Then, the dimensionless form of the load carrying capacity w is obtained in the form of:

$$
\mathrm{W}=\frac{\mathrm{h}_{1}{ }^{2} \mathrm{w}}{\mu \mathrm{Ul}^{2} \mathrm{~B}}=\frac{\mu^{*}}{12}+\int_{0}^{1} \mathrm{X} \frac{\mathrm{Q}-\mathrm{E}}{\mathrm{G}} \mathrm{dX}
$$

The non-dimensional friction force $\mathrm{F}$ on the slider and the coefficient of friction $\mathrm{f}$ are derived from:

$$
\overline{\mathrm{F}}=\frac{\mathrm{h}_{1} \mathrm{~F}}{\mu \mathrm{UlB}}=\int_{0}^{1}\left[\frac{\overline{\mathrm{s}}}{(1+\overline{\mathrm{sh}})}+\frac{\overline{\mathrm{h}}(2+\overline{\mathrm{sh}})(\mathrm{E}-\mathrm{Q})}{2 \mathrm{G}(1+\overline{\mathrm{sh}})}\right] \mathrm{dX}
$$

and

$$
\overline{\mathrm{f}}=\frac{\mathrm{lf}}{\mathrm{h}_{2}}=\frac{\overline{\mathrm{F}}}{\overline{\mathrm{W}}}
$$

respectively.

\section{Results and Discussions}

It is noticed from Eq. (11) that the non-dimensional load carrying capacity gets enhanced by

$$
\frac{\mu^{*}}{12}
$$


as can be seen from Eq. (11), in comparison with the conventional lubricant based bearing system. This is not surprising because the magnetization increases the viscosity of the lubricant. Further on, Eq. (11) suggests that the expression involved is linear with respect to the magnetization parameter and hence the increased load carrying capacity.

The fact that the load carrying capacity increases sharply with increasing magnetization, can be seen from Figs. 2-5.

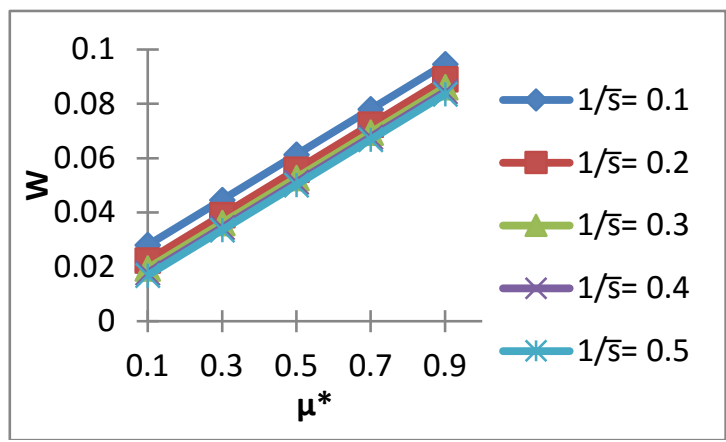

Fig. 2. Variation of Load Carrying capacity with respect to $\mu^{*}$ and $1 / \mathrm{s}$

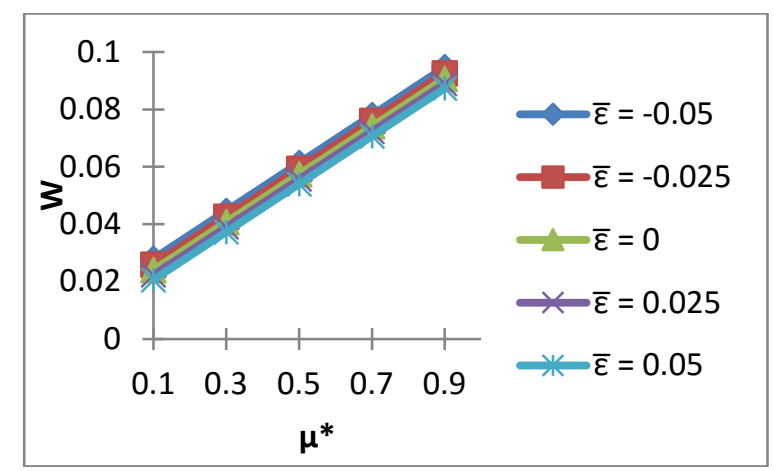

Fig. 3. Variation of Load carrying capacity with respect to $\mu^{*}$ and $\bar{\varepsilon}$

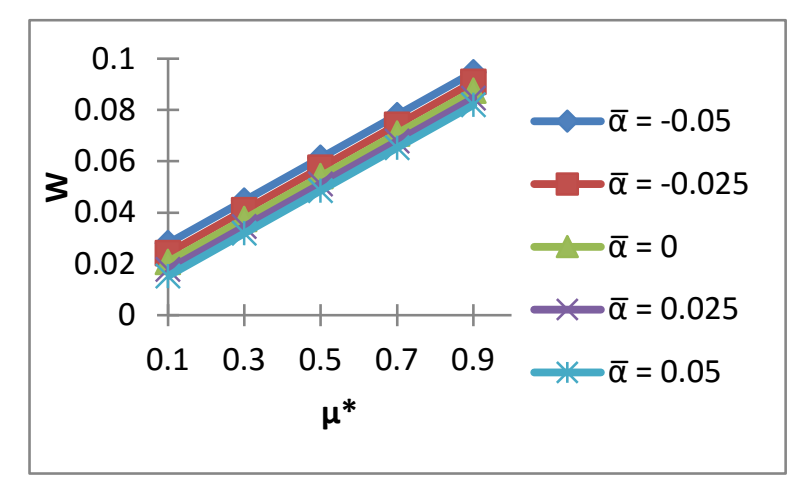

Fig.4. Variation of Load Carrying capacity with respect to $\mu^{*}$ and $\bar{\alpha}$ 


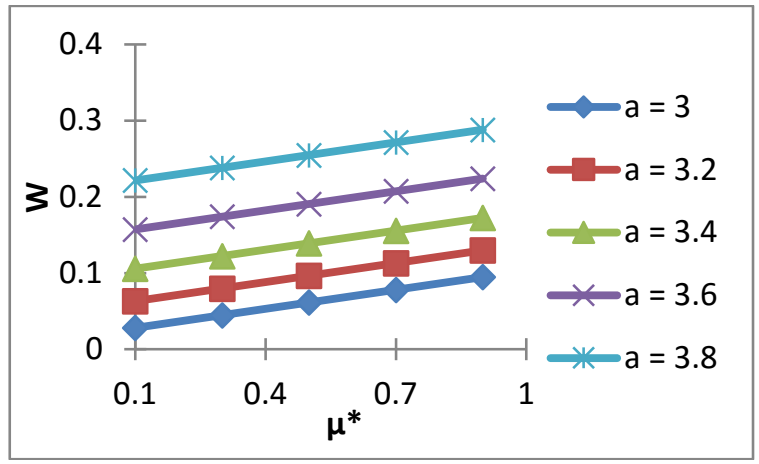

Fig.5. Variation of Load Carrying capacity with respect to $\mu^{*}$ and a.

Further on, the slip parameter causes reduced load carrying capacity as can be seen from Figs. 6-9.

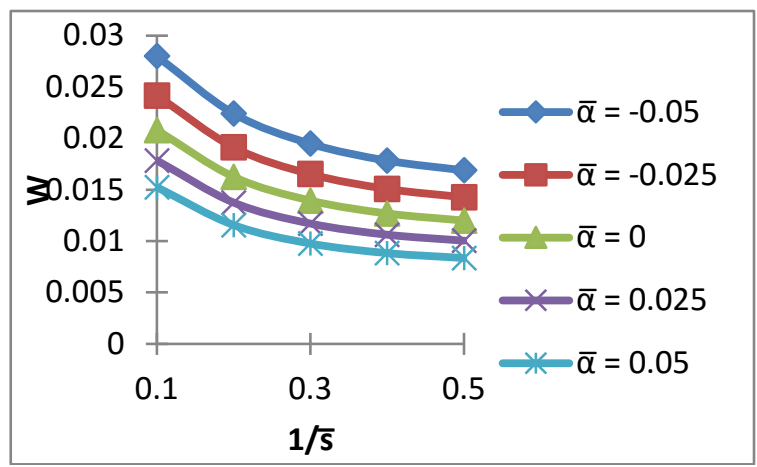

Fig. 6. Variation of Load Carrying capacity with respect to $1 / \bar{s}$ and $\bar{\alpha}$

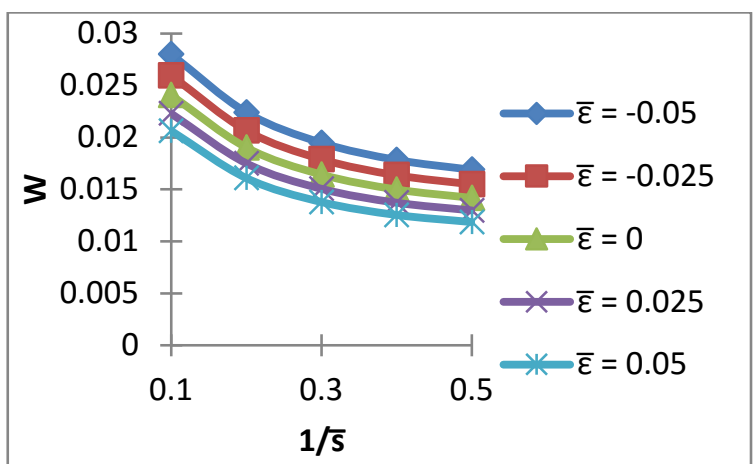

Fig. 7. Variation of Load Carrying capacity with respect to $1 / \bar{s}$ and $\bar{\varepsilon}$ 


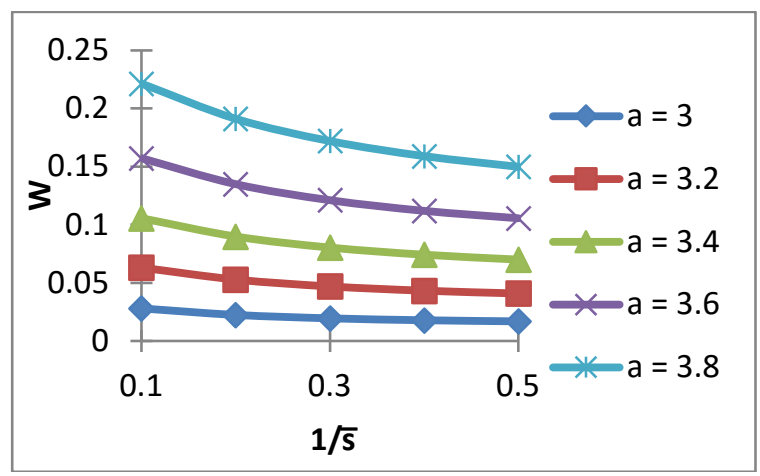

Fig.8. Variation of Load Carrying capacity with respect to $1 / \bar{s}$ and a

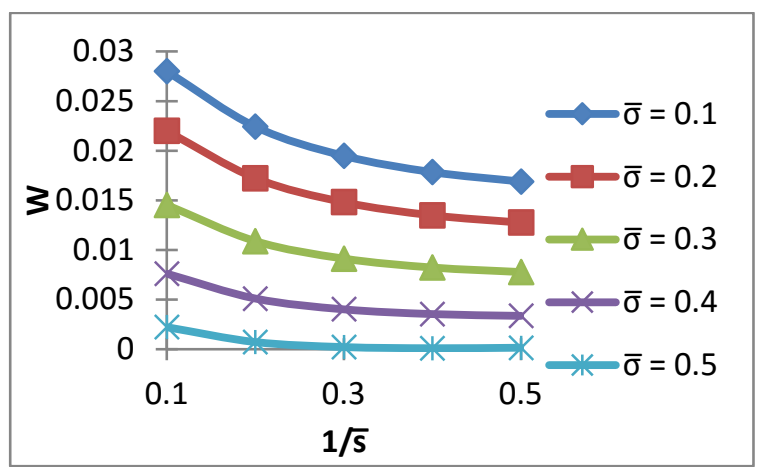

Fig.9. Variation of Load Carrying capacity with respect to $1 / \bar{s}$ and $\bar{\sigma}$

The effect of standard deviation is presented in Figs. 10-12. It is clearly seen that the load carrying capacity reduces when the standard deviation gets increased. Thus, the combined effect of slip parameter and the standard deviation associated with roughness turns in an adverse performance.

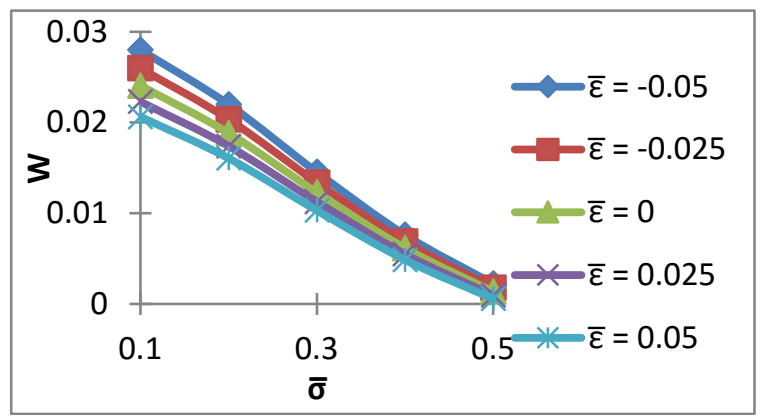

Fig. 10. Variation of Load Carrying capacity with respect to $\bar{\sigma}$ and $\bar{\varepsilon}$ 


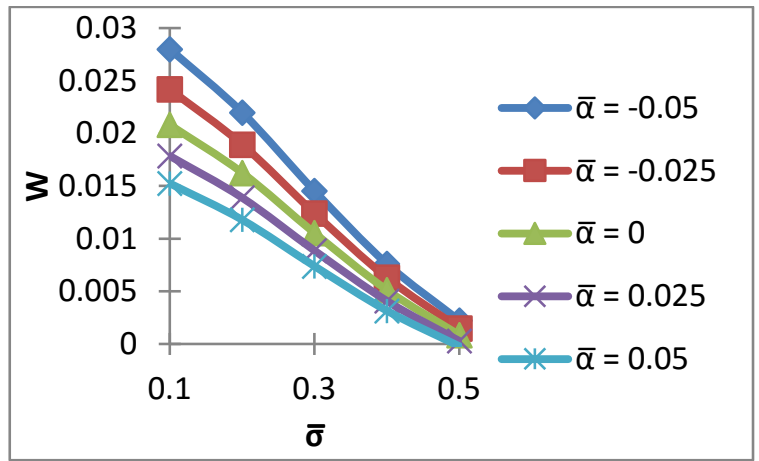

Fig. 11. Variation of Load Carrying capacity with respect to $\bar{\sigma}$ and $\bar{\alpha}$

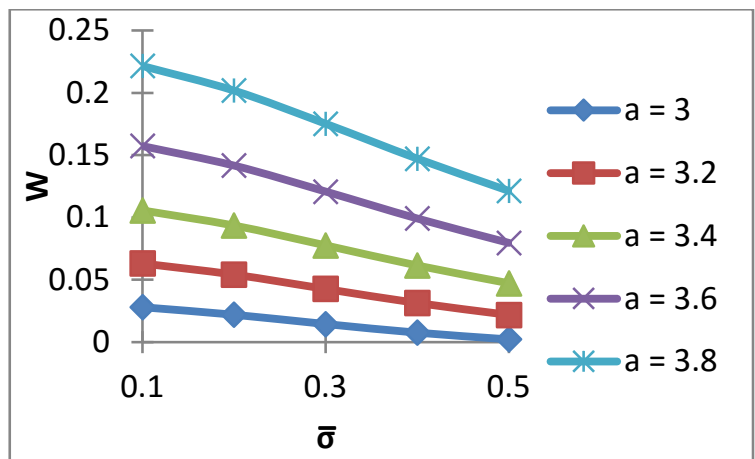

Fig. 12. Variation of Load Carrying capacity with respect to $\bar{\sigma}$ and a

The effect of skewness and variance on the load carrying capacity is shown in Fig. 13. The trends of load carrying capacity with respect to skewness is quite similar to that of the variance. In other words, the positive skewness decreases the load carrying capacity, while the load carrying capacity gets increased due to negatively skewed roughness. The variance follows the path of skewness so far as the trends of load carrying capacity are concerned. Of course, the porosity causes reduction in load carrying capacity.

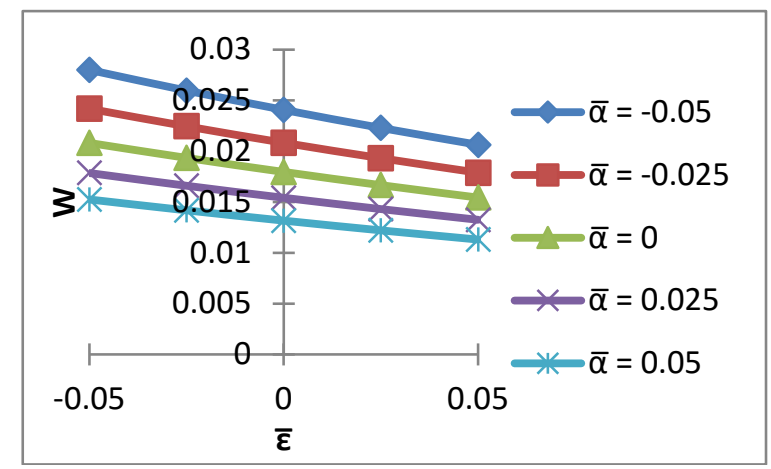

Fig. 13. Variation of Load Carrying capacity with respect to $\bar{\varepsilon}$ and $\bar{\alpha}$ 
The profile of the variation of friction is presented in Figs. 14-17. The combined effect of porosity, slip and standard deviation reduces the friction heavily. Even the magnetization reduces the coefficient of friction. However, the variance and skewness increase the friction. Besides, the effect of skewness on the variation of friction with respect to standard deviation is not that significant for lower to moderate values of skewness. It is interesting to note that the friction increases with respect to the slip parameter up to the value of slip parameter 0.15 and afterwards it decreases

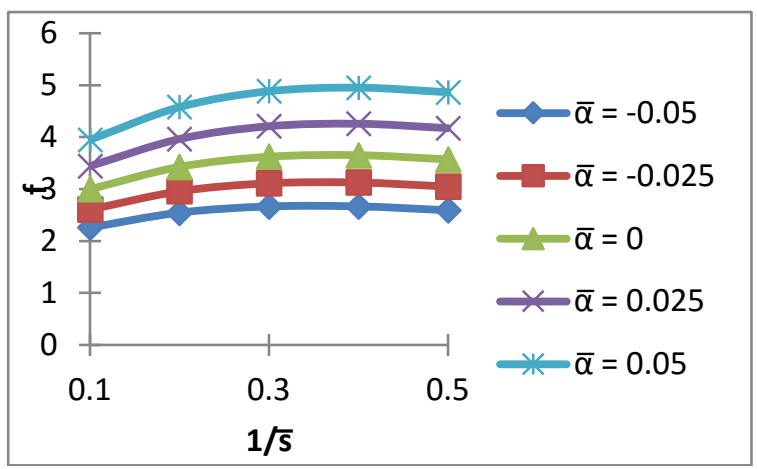

Fig. 14. Variation of friction with respect to $1 / \sqrt{s}$ and $\bar{\alpha}$

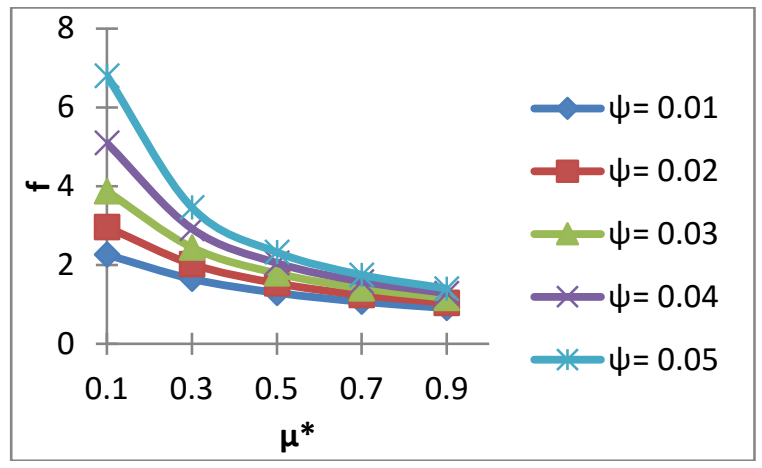

Fig. 15. Variation of friction with respect to $\mu^{*}$ and $\psi$

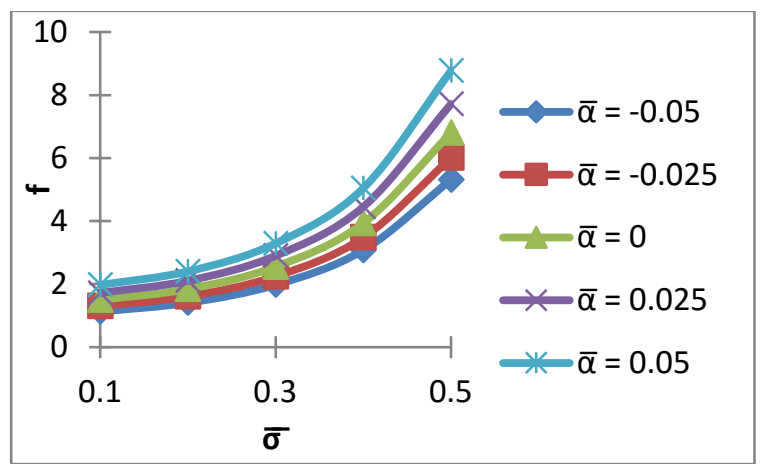

Fig. 16. Variation of friction with respect to $\bar{\sigma}$ and $\bar{\alpha}$ 


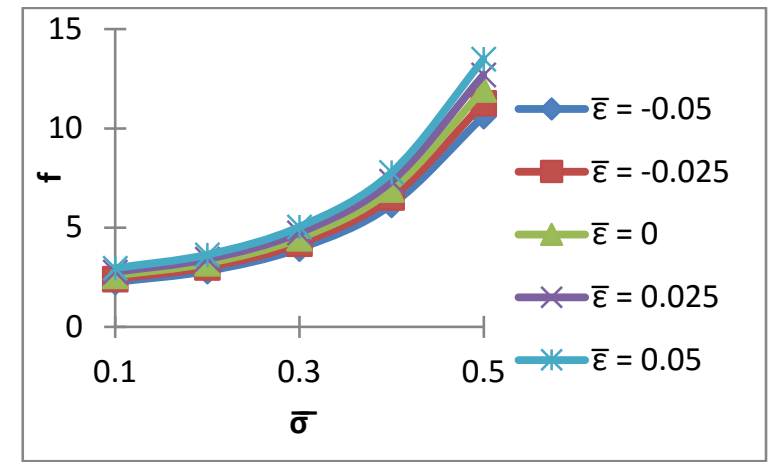

Fig. 17. Variation of friction with respect to $\bar{\sigma}$ and $\bar{\varepsilon}$

\section{Conclusions}

This article affirms that for any type of improvement in the bearing performance the slip is deserved to be at the reduced level. Hence, this study indicates that while designing the bearing system, one is required to consider the roughness aspect carefully. In spite of the fact that there are several parameters causing load reduction, there is a good amount of load supported by the bearing system, even in the absence of flow, which does not happen for conventional lubricant based bearing system. This article establishes that the adverse effect of roughness can be minimized by the ferrofluid lubrication by resorting to lower values of slip velocity. This means from bearing's life period point of view the roughness aspects must be evaluated while designing the bearing system.

Acknowledgements The authors acknowledge with thanks fruitful comments and suggestions of the reviewers and the editor.

\section{References}

Agrawal VK (1986). Magnetic fluid based porous inclined slider bearing, Wear, 107, 133-139. Ajwaliya MB (1984).On certain theoretical aspects of lubrication. Dissertation, Sardar Patel University VallabhVidyanagar, India.

AndhariaPI, Gupta JL, Deheri GM (2001). Effect of Surface Roughness on Hydrodynamic Lubrication of Slider Bearings, Tribology Transactions, 44(2).

Beavers GS, Joseph DD (1967). Boundary conditions at a naturally permeable wall, Journal of Fluid Mechanics, 30, 197-207.

Bhat MV (2003). Lubrication with a Magnetic fluid, Team Spirit (India) Pvt. Ltd, India.

Bhat MV, Patel RR (1991). Analysis of an exponential porous slider bearing lubricated with magnetic fluid, J. Eng. Technol.,S.P.Uni., 6, 19-21.

Bujurke NM, Naduvinamani NB, Benchalli SS (2005). Secant-shaped porous slider bearing lubricated with couplestress fluids, Industrial Lubrication and Tribology, 57(4), 155-160.

Cameron A (1987). Basic Lubrication Theory, Wiley Eastern Ltd., 62.

Christensen H, Tonder KC (1969a). Tribology of rough surfaces: Parametric study and comparison of lubrication models, SINTEF Report No.22/69-18, 1969a.

Christensen H, Tonder KC (1969b). Tribology of rough surfaces: Stochastic models of hydrodynamic lubrication, SINTEF Report No.10/69-18.

Christensen H, Tonder KC (1970). The hydrodynamic lubrication of rough bearing surfaces of finite width, ASME-ASLE lubrication conference, 70-Lub-7, 1970. 
Deheri GM, Andharia PI, Patel RM (2004). Longitudinally rough slider bearings with squeeze film foamed by a magnetic fluid, Industrial Lubrication and Tribology, 56(3), 177-187.

Deheri GM, Andharia PI, Patel RM (2005). Transversely rough slider bearings with squeeze film formed by a magnetic fluid, International Journal of Applied Mechanics and Engineering, 10(1), 53-76.

Naduvinamani NB, Fathima ST, Hiremath PS (2003). Hydrodynamic lubrication rough Slider bearings with couple stress fluids, Tribology International, 36(12), 949-959.

Patel SJ, Deheri GM, Patel JR (2014). Ferrofluid lubrication of a rough porous hyperbolic slider bearing with slip velocity, Tribology in Industry, 36(3), 259-268.

Patel JR, Deheri GM (2013). A Comparison of Porous Structures on the Performance of a Magnetic Fluid Based RoughShort Bearing, Tribology in Industry, 35(3), 177-189.

Patel JR, Deheri GM (2014). Slip Velocity and roughness effect on magnetic fluid based infinitely long bearings, Proceedings of International Conference on Advances in Tribology and Engineering Systems, India, 97-109.

Patel JR, Deheri GM (2015). Jenkins model based Magnetic squeeze film in curved rough circular plates considering slip velocity: A comparison of shapes, FME Transactions, 43(2), 144-153.

Patel JR, Deheri GM (2016). The effect of slip velocity on the ferrofluid based squeeze film in longitudinally rough conical plates, Journal of the Serbian Society for Computational Mechanics, 10(2), 18-29.

Patel KC, Gupta JL (1983). Hydrodynamic lubrication of a porous slider bearing with slip velocity, Wear, 85(3), 309-317.

Patel ND, Deheri GM (2011). Effect of Surface Roughness on the Performance of a Magnetic Fluid Based Parallel Plate Porous Slider Bearing with Slip Velocity, Journal of the Serbian Society for Computational Mechanics, 5(1),104-118.

PrakashJ, VijSK (1973). Hydrodynamic Lubrication of a Porous Slider, J. Mech, Eng. Sci., 15(3), 232-234.

Salant RF, Fortier AE (2004). Numerical Analysis of a Slider Bearing with a Heterogeneous Slip/No- Slip Surface, Tribology Transactions, 47(3), 328-334.

Shah RC, Bhat MV (2003). Effect of slip velocity in a porous secant-shaped slider bearing with a ferrofluid lubricant, Fizika A, 12(1), 1-8.

Shukla SD, DeheriG (2011). Surface roughness effect on the performance of a magnetic fluid based porous secant shaped slider bearing, Industrial Engineering Letters, 1(2).

Siddangauda A, Biradar TV, Nanduvinamani NB (2014). Combined effects of micropolarity and surface roughness on the hydrodynamic lubrication of slider bearings, J. of Brazilian Soc. of Mechanical Sci. and Eng., 36(1), 45-58.

Sparrow EM, Beavers GS, Hwang IT (1972). Effect of Velocity Slip on Porous-Walled Squeeze Films, Journal of Tribology, 94(3), 260-264.

Verma PDS (1986). Magnetic fluid-based squeeze film, Int. J. Eng. Sci., 24, 395-401.

Wu CW, Ma GJ, Zhou P, WuCD (2006). Low Friction and High Load Support Capacity of Slider Bearing With a Mixed Slip Surface, J. Triboloy, 128(4), 904-907. 